\title{
Uncovering Links Between Urban Studies and Network Science
}

\section{Ben Derudder ${ }^{1} \cdot$ Zachary Neal $^{2}$}

Published online: 20 February 2019

C) Springer Science+Business Media, LLC, part of Springer Nature 2019

References to "urban networks" in scholarly books and articles have grown dramatically since the 1960s (Fig. 1). Research on the topic of urban networks now extends across many social and natural science disciplines and over many scales of analysis. Seeking to identify linkages between Urban Studies and Network Science in this growing literature, this special issue is one of the first sustained efforts to bring these disciplines into closer dialog (see http://www.urbannetworks.org). Because Networks and Spatial Economics is among relatively few interdisciplinary journals devoted to the quantitative study of economic activities facilitated by spatially-embedded social and infrastructure networks, it was the logical outlet for an initial attempt at bridging between Urban Studies and Network Science.

Despite the growing frequency of scholarly references to "urban networks" and ongoing attempts to summarize the field (e.g. Neal 2013; Rozenblat and Neal Forthcoming), the fields of urban studies and network science remain largely separate. Both literatures follow their own complex and multi-layered course, which implies that analytical intersections are perforce uneven and diverse. In addition, urban network research must be considered alongside closely related research agendas, including work on "spatial networks" (Barthélémy 2011) and accessibility analysis (CondeçoMelhorada et al. 2018). As a consequence, "urban network research" does not represent a standardised and consolidated field of scholarship, but instead describes the application of network science methods to answer theoretical and empirical questions arising from urban studies. Consequently, the growing number of urban and network researchers adopting this approach vary immensely in their research questions, scales of analysis, disciplinary perspective, and intended audiences.

This diversity is evident in the contributions to this special issue, which has two complementary objectives. Firstly, the special issue aims to take stock of the diversity of, and progress made in, research at the intersection of Urban Studies and Network

Ben Derudder

Ben.Derudder@UGent.be

1 Ghent University, Ghent, Belgium

2 Michigan State University, East Lansing, MI, USA 


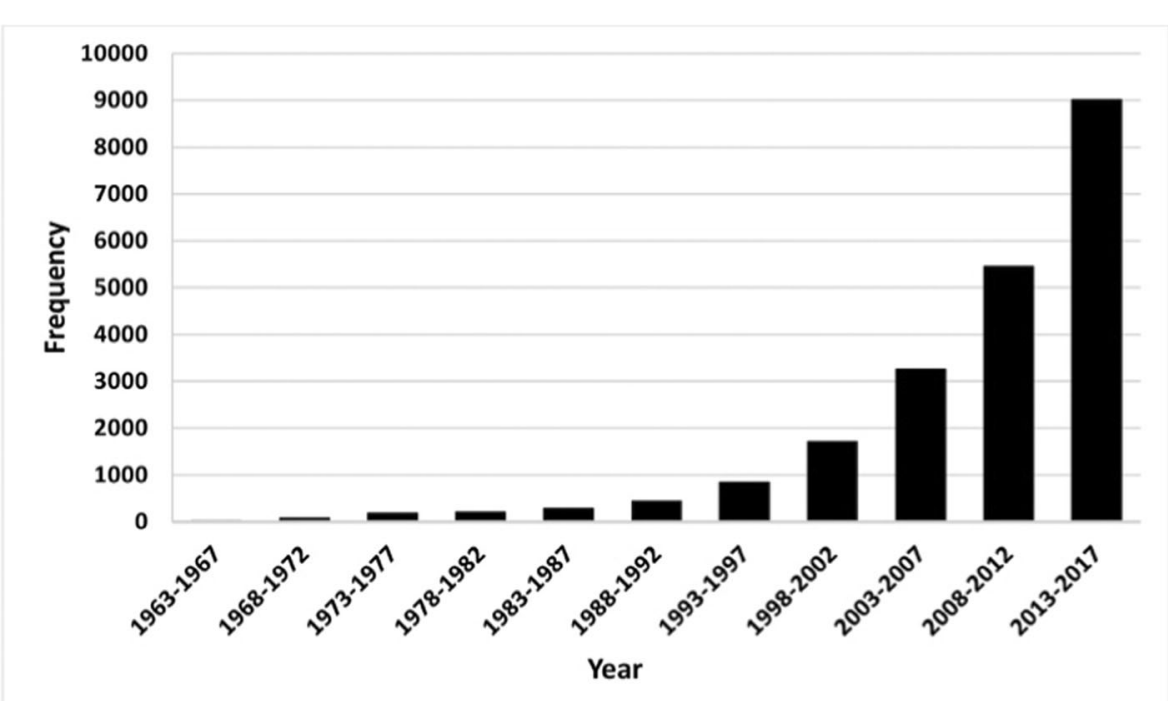

Fig. 1 Rising number of references to "urban networks" (Source Google Scholar, September 12th, 2018)

Science. Collectively the papers show how network-scientific thinking facilitates our understanding of cities, and, conversely, how urban studies have provided a useful context for developing and applying network analysis. Secondly, the special issue also tries to articulate an agenda for the next wave of urban network research by shedding light on what is not yet known about cities and networks, where these two fields remain misaligned, and how their closer integration can help move both forward. To this end, the papers included here are not simply state of the art examples of urban network research; they push the analytical boundaries of the field, and it is hoped that this opens up avenues for further research.

We believe the papers achieve these aims in several ways. For example, Liu and $\mathrm{Hu}$ (2018) show how the adoption of network methods allow urban researchers to ask new kinds of questions by analysing 'sister city' connections. Similarly, Verhetsel et al. (2018) and Natapov et al. (2018) illustrate how network perspectives can shed new light on already well-established urban research agendas, including the literature on daily urban systems and space syntax, respectively. Others explore critical issues associated with the use of network analysis to examine cities (see Marshall et al. 2018), or adopt it to plug some well-known holes in the literature on urban and regional change (e.g. analysis of the making and dissolution of research and development collaboration in a region, see Broekel and Bednarz 2018). In addition, some papers take a broad view by asking questions about the evolution of this field through bibliometric analysis (Peris et al. 2018), or about the quality of empirical evidence derived from network analyses of urban data (Neal 2018).

The diversity in the papers can be roughly traced back to their diversity along three different analytical axes, i.e. (1) the scale of analysis adopted, (2) the urban processes captured, and (3) the ontological status ascribed to the "networks" under study (cf. Neal 2014). First, although it would probably be more apt to speak of a scalar continuum, the papers broadly substantiate Neal's (2013) heuristic identification of three levels of urban networks: micro, meso, and macro. These levels build upon one another, but 
tend to require distinctive network-analytical approaches that make it possible to consider different types of questions. At one extreme, micro-urban networks focus on the networks that exist within cities, as for example in Bielik et al.'s (2018) analysis of how an urban street network influences pedestrian movement flows and therefore the chances of encounter. As access to movement flows is shown to be highly correlated with both neighbourhood walkability and social interaction, this clearly corroborates the importance of a network approach to our understanding of urban structure. Another analysis of intra-city networks can be found in Brelsford and De Bacco (2018), who show the presence of network-based peer effects in participation in an incentive-based conservation program in neighbourhoods in Las Vegas. At the opposite extreme, macro-urban networks focus on networks between cities, often even at the global scale (cf. Derudder and Taylor 2017), as in Pan et al. (2018) where it is shown how inter-firm service relationships of Chinese firms connect China to the global economy by building up global urban networks from Hong Kong. A similar scale of analysis can be found in Berli et al. (2018), who study the centrality of port and non-port cities in Australia in a hybrid global maritime and road network. And finally, meso-level studies focus on regional settlement systems, and are especially germane in so-called 'polycentric urban regions' (Liu et al. 2016) where urbanization, suburbanization, and peri-urbanization coalesce. In such cases, 'nodalization' - defining the nodes to be connected - can become a complex task. In Caset et al.'s (2018) study of the (im)balance between infrastructure connectivity and land use characteristics in the Brussels Capital Region, this is tackled by defining the stations in the Regional Express Railway (RER) network as the units of analysis. Meanwhile, Verhetsel et al. (2018) shed fresh light on the Daily Urban Systems literature by using community detection analysis at the lowest politicoadministrative level to define these systems and their different dimensions. These scalar differences do not imply that there is a critical scalar disjuncture in the literature that would render the notion "urban network" incoherent. For example, Neal (2018) shows how researchers studying urban networks - both networks of cities and networks in cities - have sometimes participated in the same kinds of exercises, for example by exploring whether the network has small world characteristics.

Second, and cross-cutting this scalar focus, are the different urban processes captured by the network-analytical framework. These urban processes include commuting and transport networks, but also social and economic networks alongside innovation and policy networks. Verhetsel et al.'s (2018) and Berli et al.'s (2018) above-referenced papers are examples of commuting and transport networks, respectively. Pan et al.'s (2018) focus is on urban-economic networks as they analyse the inter-city relations of globalising Chinese cities, while Bielik et al. (2018) and Brelsford and De Bacco (2018) primarily deal with social interactions in urban environments. The focus on urban policy networks appears in Liu and $\mathrm{Hu}$ (2018), who argue that "sister city relations" - relations between city governments - represent a significant mediator in affecting inter-city networks. And finally, innovation and R\&D networks are tackled head on in Broekel and Bednarz (2018), who use separable temporal exponential random graph models to dissect the formation and dissolution of R\&D collaboration networks in the German biotechnology industry. In addition to studies focusing on specific sets of processes, some papers combine these processes as they explicitly overlap and intersect. For example, in their study of ride sharing in New York City, Shen et al. (2018) adopt a socio-technical perspective by proposing a framework to determine the specific urban activity of ride sharing systems in 
cities, claiming that the framework can effectively determine urban activity and location patterns for vehicle allocation, price strategy, and route planning for ride sharing systems. In general, this diversity of processes is a reflection of the power of network analysis, but at the same time the problem of observational equivalence looms large (Van Meeteren et al. 2016): the fact that these different urban processes can all be meaningfully represented in a network does not mean they automatically refer to the same object, even if the degree of 'isomorphism' or' 'homology' is sizable. The question thus remains to what extent inter-governmental collaborations, inter-firm networks, maritime networks, etc. add up to a generalized "urban networks" concept.

The third and final axis along which the different papers differ is the ontological status of the networks studied in the different papers. When we think of the urban world as being constituted by 'cities as networks within networks of cities' (to paraphrase Berry 1964), in principle we do nothing more than invoking intuitive network associations. In this special issue, these associations have a consistent graph-theoretical basis. That is, they share in common the ontological assumption that a network or networks can be observed, measured, and represented as a graph. However, although the intuitive correspondence between graph-theoretical conceptions of networks and urban phenomena may seem to provide a consistent starting point for urban network research as covered in this special issue, it would be a 'naive objectivist' (Sayer 1992, p. 44) fallacy to assume that intuition automatically validates this approach and the urban network under study corresponds to a research object (van Meeteren et al. 2016). The degree to which the "urban network" under study is assumed to be an actually existing object of study or a mathematical representation for analytic convenience varies across papers. For example, although the visibility graphs in Natapov et al. (2018), are deemed to be representations of navigational decisions within the street network, the authors note that the organisation of these visuospatial networks share morphological similarities with other natural networks, suggesting that common organizational principles underlie network structure. This echoes Bettencourt and West's (2010) suggestion of the possibility of a 'unified theory of urban living' which would corroborate the starting point of Neal's (2018) analysis of whether small world network structures are ubiquitous in urban networks. However, there are also counterarguments to ascribing ontological status to urban networks, which would assume these exist independent from an abstraction or a deliberate choice on the part of the researchers. Some of these counterarguments surface in Neal's (2018) findings, as he shows how the absence of a formal index guided by a specific decision rule may overestimate the ubiquity of small world structures. This doubt over the possibility of a unified understanding of urban networks is shared by many who would otherwise be willing to buy into network-analytical approaches (see O’Sullivan and Mason 2015). Marshall et al. (2018) provide a stark example of why it pays off to continue to see urban networks as abstractions and/or representations rather than as research objects that speak for themselves. Using research into street networks as an example, they show how even the most rigorous formalisation of these street networks as graphs cannot overcome that these are complex objects of study. They can therefore be represented differently, which has fundamental implications for the outcomes of any study. Intuitive or naïve specifications of urban networks (such as street networks) that ignore this plurality may thus be used as the input to high-level network models, but nonetheless give little or even misleading insight into the urban fabric. 
The rapid growth in the size, scope, and scale of urban network research has left the field of urban network research invigorated. But the diversity instilled by the differences in scale, processes, and ontological outlook paint an overall picture of a literature some might describe as fragmented, but which we would prefer (adopting a network view) to describe as composed of multiple communities. This is confirmed by Peris et al. (2018), who, drawing on a bibliometric analysis, identify different schools of thought in the urban networks literature structured by conceptual, methodological and empirical differences. Because the fields of Urban Studies and Network Science are themselves multifaceted, it is inevitable that the emerging field of urban networks will have similarly fuzzy boundaries. However, we believe that through increasing reflection about the utility of network scientific techniques for answering urban questions, for example in this special issue and other related venues (e.g. http://www.urbannetworks.org), we will find increasing evidence for Smith and Timberlake's (1993) assertion that it represents "a perfect marriage of a theoretical approach and an analytic technique" (p. 197).

Publisher's Note Springer Nature remains neutral with regard to jurisdictional claims in published maps and institutional affiliations.

\section{References}

Barthélemy M (2011) Spatial Networks. Phys Rep 499(1-3):1-101

Berli J, Bunel M, Ducruet C (2018) Sea-land interdependence in the global maritime network: the case of Australian port cities. Networks and Spatial Economics. https://doi.org/10.1007/s11067-018-9403-4

Berry BJ (1964) Cities as Systems within Systems of Cities. Pap Reg Sci 13(1):147-163

Bettencourt L, West G (2010) A unified theory of urban living. Nature 467:912-913

Bielik M, König R, Schneider S, Varoudis T (2018) Measuring the impact of street network configuration on the accessibility to people and walking attractors. Networks and Spatial Economics. https://doi. org/10.1007/s11067-018-9426-x

Brelsford C, De Bacco C (2018) Are 'Water Smart Landscapes' Contagious? An epidemic approach on networks to study peer effects. Networks and Spatial Economics. https://doi.org/10.1007/s11067-0189416-z

Broekel T, Bednarz M (2018) Disentangling link formation and dissolution in spatial networks: an application of a two-mode STERGM to a project-based R\&D network in the German biotechnology industry. Networks and Spatial Economics. https://doi.org/10.1007/s11067-018-9430-1

Caset F, Vale DS, Viana CM (2018) Measuring the accessibility of railway stations in the Brussels Regional Express Network: a node-place modeling approach. Networks and Spatial Economics. https://doi. org/10.1007/s11067-018-9409-y

Condeço-Melhorado A, Reggiani A, Gutiérrez J (2018) New Data and Methods in Accessibility Analysis. Netw Spat Econ 18:237-240

Derudder B, Taylor PJ (2017) Central flow theory: comparative connectivities in the world-city network. Reg Stud 52(8):1029-1040

Liu X, Derudder B, Wu K (2016) Measuring polycentric urban development in China: an intercity transportation network perspective. Reg Stud 50(8):1302-1315

Liu X, Hu X (2018) Are 'sister cities' from 'sister provinces'? An exploratory study of sister city relations (SCRs) in China. Networks and Spatial Economics. https://doi.org/10.1007/s11067-018-9408-Z

Marshall S, Gil J, Kropf K, Tomko M, Figueiredo L (2018) Street network studies: from networks to models and their representations. Networks and Spatial Economics. https://doi.org/10.1007/s11067-018-9427-9

Natapov A, Czamanski D, Fisher-Gewirtzman D (2018) A Network Approach to Link Visibility and Urban Activity Location. Networks and Spatial Economics. https://doi.org/10.1007/s11067-018-9411-4

Neal ZP (2013) The Connected City: how Networks are Shaping the Modern Metropolis. Routledge, New York

Neal ZP (2014) The devil is in the details: differences in air traffic networks by scale, species, and season. Soc Networks 38:63-73 
Neal ZP (2018) Is the urban world small? The evidence for small world structure in urban networks. Networks and Spatial Economics. https://doi.org/10.1007/s11067-018-9417-y

O’Sullivan D, Manson SM (2015) Do physicists have geography envy? And what can geographers learn from it? Ann Assoc Am Geogr 105(4):704-722

Pan F, He Z, Liang J (2018) World City Networks Shaped by the Global Financing of Chinese Firms: A Study Based on Initial Public Offerings of Chinese Firms on the Hong Kong Stock Exchange, 1999-2017. https://doi.org/10.1007/s11067-019-09450-z

Peris A, Meijers E, Van Ham M (2018) The evolution of the systems of cities literature since 1995: schools of thought and their interaction. Networks and Spatial Economics. https://doi.org/10.1007/s11067-0189410-5

Rozenblat C, Z P N (Forthcoming) Handbook of Cities and Networks. Edward Elgar, Northampton

Sayer A (1992) Method in social science, a realist approach, 2nd edn. Routledge, London

Shen B, Zheng W, Carley KM (2018) Urban Activity Mining Framework for Ride Sharing Systems based on Vehicular Social Networks. https://doi.org/10.1007/s11067-019-09452-x

Smith DA, Timberlake M (1993) World cities: A political economy/global network approach. Research in Urban. Sociology 3:181-207

Van Meeteren M, Neal Z, Derudder B (2016) Disentangling agglomeration and network externalities: A conceptual typology. Pap Reg Sci 95(1):61-80

Verhetsel A, Beckers J, De Meyere M (2018) Assessing Daily Urban Systems (DUSs) in Belgium: a network approach based on commuting flows, with special attention to gender and income differences. Networks and Spatial Economics. https://doi.org/10.1007/s11067-018-9425-y 